\title{
Comparative Isotherms Studies on Adsorptive Removal of Congo Red from Wastewater by Watermelon Rinds and Neem-Tree Leaves
}

\author{
M. B. Ibrahim 1 , S. Sani' ${ }^{2}$ \\ ${ }^{1}$ Department of Pure and Industrial Chemistry, Bayero University, Kano, Nigeria \\ ${ }^{2}$ Department of Applied Chemistry, Federal University, Dutsin-Ma, Nigeria \\ Email: mbibrahim.chm@buk.edu.ng, sadiqsani123@gmail.com \\ Received 15 August 2014; revised 10 September 2014; accepted 6 October 2014 \\ Copyright (C) 2014 by authors and Scientific Research Publishing Inc. \\ This work is licensed under the Creative Commons Attribution International License (CC BY). \\ http://creativecommons.org/licenses/by/4.0/

c) (i) Open Access

\section{Abstract}

Equilibrium adsorption studies for detoxification of Congo Red (CR) dye from single component model wastewater by powdered watermelon rinds and neem leaves adsorbents were carried out with the view to test the applicability of the adsorption process to Langmuir, Freundlich, Temkin, Dubinin-Radushkevich and Harkins-Jura isotherm models. The values of correlation coefficient, $\mathbf{R}^{2}$ (0.9359 - 0.9998), showed that all the experimental data fitted the linear plots of the tested isotherm models. Dubinin-Radushkevich's monolayer maximum adsorption capacity $\mathrm{q}_{\mathrm{D}}(20.72$ $26.06 \mathrm{mg} / \mathrm{g})$ is better than Langmuir's $q_{\mathrm{m}}(18.62-24.75 \mathrm{mg} / \mathrm{g})$ for both adsorbents with the capacities higher for adsorption on watermelon rind than on neem leaves. Values of Langmuir separation factor $\left(R_{L}\right)$ suggest unfavourable adsorption processes (i.e. chemisorption) of the dye on both the adsorbents, while Freundlich constant $\left(n_{F}\right)$ indicates unfavourable process only for $C R$ adsorption onto neem leaves. The Dubinin-Radushkevich's mean free energy of adsorption, $E$ (0.29 - 0.32 $\mathrm{kJ} / \mathrm{mol})$, suggests physical adsorption processes. Values for Temkin's heat of adsorption, $\mathbf{b}_{\mathrm{T}}(-0.95$ to $0.74 \mathrm{~kJ} / \mathrm{mol}$ ), also show physical adsorption process.

\section{Keywords}

Adsorption Isotherms, Congo Red, Neem Leaves, Watermelon Rinds

\section{Introduction}

Water is an essential necessity for human survival whose global demand doubles every 21 years and its scarcity

How to cite this paper: Ibrahim, M.B. and Sani, S. (2014) Comparative Isotherms Studies on Adsorptive Removal of Congo Red from Wastewater by Watermelon Rinds and Neem-Tree Leaves. Open Journal of Physical Chemistry, 4, 139-146. 
affects $40 \%$ of the world population (about 1.2 billion) projected to reach 2.7 billion by 2025 with water borne diseases claiming annual death rate of 5 to 10 million [1]. About $71 \%$ of the earth surface is occupied by water of which only about $0.05 \%$ is accessible for human consumption while the bulk of the remaining comprises of the inaccessible seawater, groundwater, swamps and frozen polar ice caps [2]. The scarcity of water is due to rapid population growth, increased industrialization and decreased amounts of rainfall in the previous decades [3]. More so, water pollution by untreated synthetic dye effluents released from industries has been identified as one of the consequences of worsening situation of water scarcity in the society.

Dyes are complex chemical substances that bear stable aromatic rings synthesized to impart strong and persistent colour that does not degrade on exposure to light [4] [5]. Although natural dyes are still in rare use, almost all dyes in use today are synthetic with annual production of over $7 \times 10^{5}$ tonnes of which azo dyes account for $60 \%-70 \%$ [6]. About $10 \%-15 \%$ of these dyes are discharged as untreated effluents during the dyeing process [7] [8]. The untreated effluent discharged from textile, cosmetics, pulp and paper, paint, pharmaceutical, food, carpet and printing industries is highly coloured due to large amounts of unfixed dyes that remained during colouring and washing [9].

Untreated dye effluents are toxic and non-biodegradable environmental pollutants that prevent re-establishment of microbial populations, degrade water quality permanently, cause allergy, dermatitis, cancer, skin irritation, dysfunction of kidneys, liver and reproductive system in humans [10] [11]. In other words, it could leach into and pollute surface and ground waters used for drinking; affect the photosynthesis of aquatic plants by hindering penetration of light into the water; and may cause suffocation of aquatic flora and fauna due to anaerobic degradation of azo dyes into highly lethal substances [12]-[14].

Thus, to overcome the challenges of water scarcity and safe exploitation that attracted much attention from government organizations and water industries globally, it has become necessary to develop cost-effective technologies for water/wastewater treatment, reclamation, recycling and reuse for sustainable industrial and agricultural development.

Traditional and conventional techniques usually employed for the treatment of dye wastewater consist of biological, physical and chemical methods most of which are becoming inadequate due to large variability of the composition of dye wastewaters. In other words, most of these techniques are often ineffective, expensive, complicated, time-consuming and require highly-skilled personnel especially when the levels of dissolved dye adsorbates are in the range of $1-100 \mathrm{mg} / \mathrm{L}$ [15]. Similarly, adsorption methods using conventional adsorbents (e.g. activated carbons) poses the disadvantages of sludge disposal problems and high costs of operation, maintenance, adsorbent purchase and sludge regeneration [16] [17].

However, proposed adsorption techniques using living and dead biomass as adsorbents are relatively cheaper, environmentally friendlier and more efficient than conventional adsorbents for the removal of dyes from wastewater even at trace level. Non-conventional adsorption method utilizes the ability of agricultural waste materials to accumulate dye pollutants from waste streams by purely physico-chemicals pathways of uptake. Their adsorption capacities are studied using adsorption equilibrium isotherms under such optimized conditions as agitation time, adsorbent dose, adsorbents particle size, initial dye concentration and initial $\mathrm{pH}$ of dye [17]-[19].

Agricultural solid wastes and by-products are renewable resources available in large quantities with little or no value in most countries. Their utilization as good source of raw materials for dye removal poses the dual advantages of effective wastewater treatment and waste management. They usually have high molecular weight due to the presence of lignin, cellulose and hemicelluloses components [20]. Many agricultural waste adsorbents (rice husks, corncob, coir-pith, plum kernels, bagasse pith, nut shells, fruit peels, leaf powders, spent tea leaves, fruit shells, seed husk, sawdust, hyacinth root, etc.) were reported as cost-effective alternative low cost adsorbents removal of dyes from wastewater in the recent past decades [21].

\section{Materials and Methods}

\subsection{Adsorbents Preparation}

Neem tree (Azadirachta indica) leaves were collected from twigs of a number of matured tall neem trees within and near the main campus of Umaru Musa Yar'adua University, Katsina. The samples were thoroughly washed with tap-water, rinsed copiously with distilled water to remove dust and any other soluble substances. The leaves were allowed to air dry under shade at room temperature until they become crisp. The dried leaves samples were then pulverized with a mechanical grinder into a powdered; and then dried overnight for 16 hours in 
an oven at a temperature of $65^{\circ} \mathrm{C}$. The oven-dried neem-tree leaves powder (NLP) samples were sieved to the working sizes of $75-300 \mu \mathrm{m}$ using electronic sieve shaker and the fractions preserved in separately labelled air-tight plastic containers according to their particle sizes. Similar procedure was carried out on sliced pieces of fresh watermelon (Citrullus lanatus) rinds samples, collected from local fruit vendors at Kofar Kaura and Central Market in Katsina Metropolis, with the powdered fractions (WRP) separately preserved in plastic containers [21] [22].

The analytical grade Congo red dye supplied by BDH Laboratory was used as received. Stock solution of the dye was prepared by dissolving $1 \mathrm{~g}$ solute in $1000 \mathrm{~cm}^{3}$ volumetric flasks to make $1000 \mathrm{mg} / \mathrm{L}$ of the dye solution [23]. Model and working calibration standards were prepared by serial dilution of the stock solution.

\subsection{Batch Adsorption Technique}

Experiments on the adsorption of Congo red by the adsorbents (WRP and NLP) were carried out by batch method and the influence of various parameters such as contact time (5 - $240 \mathrm{~min})$, adsorbent dosage (100 - 500 $\mathrm{mg}$ ), particle size ( $\leq 75 \mu \mathrm{m}, \leq 150 \mu \mathrm{m}, \leq 250 \mu \mathrm{m}, \leq 300 \mu \mathrm{m}$ and $>300 \mu \mathrm{m}$ ), initial dye concentration (5 $300 \mathrm{mg} / \mathrm{L})$ and initial dye $\mathrm{pH}(2-12)$ were studied at constant agitation speed of $300 \mathrm{rpm}$ and room temperature $\left(25^{\circ} \mathrm{C}\right)$ in triplicates. The adsorption measurements were conducted by mixing various amounts of adsorbent in $150 \mathrm{~cm}^{3}$ Erlenmeyer glass flasks containing $50 \mathrm{~cm}^{3}$ of dye solution of known concentration. The initial $\mathrm{pH}$ of the dye solutions were adjusted to the desired values by adding few drops of $0.1 \mathrm{M} \mathrm{HCl}$ or $0.1 \mathrm{M} \mathrm{NaOH}$ aqueous solutions. The solutions were agitated using orbital shaker for a predetermined time to attain equilibrium after which, the samples were removed and the supernatant solution was separated from the adsorbent by filtration using Whatman No. 41 filter paper, discarding the first few volume (3 - 4 drops) of the filtrate [24]. The filtrates were used for analyses using UV-visible spectrophotometer, reporting each data point as an average value of the triplicates recorded. In each case, the percentage adsorption and substrate's equilibrium adsorption capacity, $q_{e}$ (mg/g) were evaluated using Equations (1) and (2) respectively.

$$
\begin{gathered}
\% \text { Adsorption }=\left[\frac{C_{o}-C_{e}}{C_{o}}\right] \times 100 \\
q_{e}=\frac{V\left(C_{o}-C_{e}\right)}{W}
\end{gathered}
$$

where $C_{o}(\mathrm{mg} / \mathrm{L})$ is the initial dye concentration, $C_{e}$ is the concentration at equilibrium or predetermined time $t, V(\mathrm{~L})$ is the volume of dye solution used and $W$ (g) is the weight of the adsorbent. The data obtained were tested against the linear forms of Langmuir, Freundlich, Temkin, Dubinin-Radushkevich (D-R) and HarkinsJura isotherms, respectively represented as;

$$
\begin{gathered}
\frac{C_{e}}{q_{e}}=\frac{1}{K_{L} q_{m}}+\frac{C_{e}}{q_{m}} \\
\ln q_{e}=\ln K_{F}+n \ln C_{e} \\
q_{e}=B_{T} \ln A_{T}+B_{T} \ln C_{e} \\
\ln q_{e}=\ln q_{D}-B_{D} \varepsilon^{2} \\
\frac{1}{q_{e}^{2}}=\left(\frac{B_{H J}}{A_{H J}}\right)-\left(\frac{1}{A_{H J}}\right) \log _{10} C_{e}
\end{gathered}
$$

where $C_{e}$ is any liquid phase concentration of the dye in equilibrium with the adsorbent, $q_{e}$ is equilibrium adsorption capacity of the adsorbent, $q_{m}$ is monolayer capacity, $q_{D}(\mathrm{mg} / \mathrm{g})$ is the theoretical monolayer saturation capacity of adsorbent, $K_{L}$ is Langmuir adsorption constant, $K_{F}$ is Freundlich constant for relative adsorption capacity of adsorbent, $A_{T}$ is the Temkin isotherm equilibrium binding constant $(\mathrm{L} / \mathrm{g}), B_{T}$ is the Temkins heat of adsorption, $A_{H J}$ is Harkins-Jura isotherm parameter which accounts for multilayer adsorption and explains the existence of heterogeneous pore distribution, while $B_{H J}$ is the isotherm constants [24]. 


\section{Results and Discussion}

To have an insight into the adsorption behaviours of CR dye onto watermelon rinds and neem leaves samples and to gain the optimal fitting of theoretical model, the experimental data from batch experiment were analyzed using five two-parameter isotherm equations (Langmuir, Freundlich, Dubinin-Radushkevich (D-R), Temkin and Harkins-Jura), in which linear regression analysis was used to evaluate whether the theoretical models have better or worse fit for the experimental data. The respective parameters of these isotherm models have been enumerated in Table 1.

\subsection{Langmuir Isotherm}

Based on the relationship of adsorption capacity for CR dye adsorption onto the adsorbents and the equilibrium concentrations, the Langmuir adsorption isotherms are modeled and presented in Figure 1. According to these

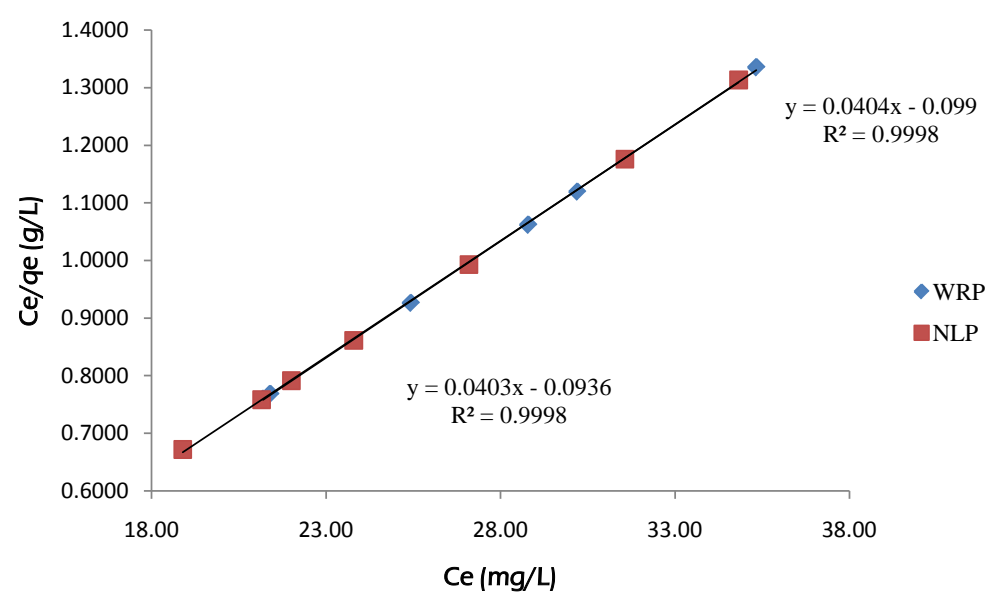

Figure 1. Langmuir isotherm plot for CR adsorption onto WRP and NLP.

Table 1. Isotherm parameters for CR adsorption onto WRP and NLP.

\begin{tabular}{|c|c|c|c|}
\hline \multicolumn{2}{|c|}{ Adsorption Isotherm Models and Parameters } & \multirow{2}{*}{$\begin{array}{c}\text { Watermelon Rinds } \\
24.75\end{array}$} & \multirow{2}{*}{$\begin{array}{c}\text { Neem-Tree Leaves } \\
24.81\end{array}$} \\
\hline Langmuir & $q_{m}(\mathrm{mg} / \mathrm{g})$ & & \\
\hline & $K_{L}$ & -0.4081 & -0.4306 \\
\hline & $R_{L}$ & -0.0082 & -0.0078 \\
\hline & $R^{2}$ & 0.9998 & 0.9998 \\
\hline \multirow[t]{3}{*}{ Freundlich } & $\left|n_{F}\right|$ & 10.13 & 3.78 \\
\hline & $K_{F}$ & 37.7204 & 37.3488 \\
\hline & $R^{2}$ & 0.9935 & 0.9919 \\
\hline \multirow[t]{4}{*}{ Temkin } & $b_{T}(\mathrm{~kJ} / \mathrm{mol})$ & -0.9212 & 0.7374 \\
\hline & $B_{T}$ & -2.6896 & -2.6164 \\
\hline & $A_{T}$ & $1.47 \times 10^{-6}$ & $1.11 \times 10^{-6}$ \\
\hline & $R^{2}$ & 0.9947 & 0.9932 \\
\hline \multirow[t]{4}{*}{ Dubinin-Redushkevich } & $B_{D}\left(\mathrm{~mol}^{2} / \mathrm{J}^{2}\right)$ & $6 \times 10^{-6}$ & $5 \times 10^{-6}$ \\
\hline & $E(\mathrm{~kJ} / \mathrm{mol})$ & 0.2887 & 0.3162 \\
\hline & $q_{D}(\mathrm{mg} / \mathrm{g})$ & 25.94 & 26.06 \\
\hline & $R^{2}$ & 0.9574 & 0.9359 \\
\hline \multirow[t]{3}{*}{ Harkins-Jura } & $A_{H J}$ & -1667 & -1667 \\
\hline & $B_{H J}$ & -0.8333 & -0.8333 \\
\hline & $R^{2}$ & 0.9908 & 0.9889 \\
\hline
\end{tabular}


isotherm curves, the Langmuir isotherm parameters are calculated and listed in Table 1.

As shown in Table 1, CR adsorption on both adsorbents have the same value of linear regression coefficient, $R^{2}$ (0.9998), suggesting that the experimental data agreed closely with each other. However, the negative values of $R_{L}$ and $K_{L}$ indicates unfavourable adsorption of the dye onto the adsorbents [25].

\subsection{Freundlich Isotherm}

Based on the relationship of adsorption capacity for CR dye adsorption onto the adsorbents and the equilibrium concentrations, the Freundlich adsorption isotherms are correlated and given in Figure 2, while the isotherm parameters are as presented in Table 1.

From the Table 1, CR adsorption on the adsorbents have a range of values of linear regression coefficient, $R^{2}$ (0.9913 - 0.9935), demonstrating that the experimental data fitted well with the Freundlich isotherm equation, third to the Langmuir isotherm. Moreover, it was reported that the Freundlich isotherm constant can be used to explore the favourability of adsorption process. The adsorption process is said to be favourable when the value of $n_{F}$ satisfies the condition $|1|<n_{F}<|10|$, otherwise it is unfavourable. While the $n_{F}$ values in Table 1 for adsorption of CR on watermelon are situated outside the range of 1 - 10 indicating unfavourable adsorption process, the values for CR adsorption on neem leaves are within the range of 1 - 10, demonstrating favourable adsorption process [26] [27].

\subsection{Temkin Isotherm}

Figure 3 illustrates the Temkin isotherm model for the dye adsorption onto the adsorbents from which the relevant isotherm parameters are listed in Table 1. It can be discovered in Table 1 that the values of $R^{2}$ are positioned within 0.9932 - 0.9947 , which gave a close fit to the CR adsorption on watermelon rind and neem leaves samples, values next only to Langmuir's model. This outcome suggests that the experimental data fitted better with the Temkin isotherm model [28]. Furthermore, it can also be discovered in Table 1 that the adsorption heat of CR adsorption on watermelon rind and neem leaves samples was restricted within -0.92 to $0.74 \mathrm{~kJ} / \mathrm{mol}$.

\subsection{Dubinin-Redushkevich Isotherm}

Making the linear plot according to adsorption capacity for CR dye adsorption onto the adsorbents and the equilibrium concentrations, the Dubinin-Radushkevich (D-R) adsorption isotherms (Figure 4) was obtained. Corresponding to which, the isotherm parameters were calculated as in Table 1.

The values of linear regression coefficient $\left(R^{2}\right)$ are in the range of $0.9359-0.9574$, revealing that the experimental data fitted well with the Dubinin-Radushkevich (D-R) isotherm model. Moreover, it is reported that when the value of $E$ is below $8 \mathrm{~kJ} / \mathrm{mol}$, the adsorption process can be considered as the physical adsorption. In contrast, if the value of $E$ is located in the range of $8-16 \mathrm{~kJ} / \mathrm{mol}$, it is the chemical adsorption. From Table 1, it can be observed that the obtained values of mean free energy, $E$, are limited within the range of $0.29-0.32$

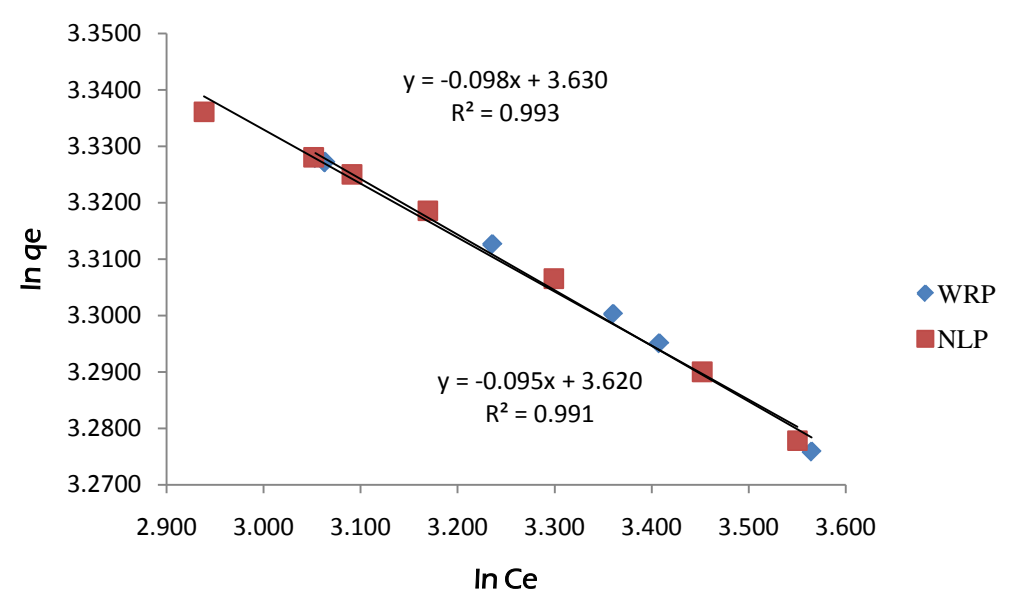

Figure 2. Freundlich isotherm plot for CR Adsorption onto WRP and NLP. 
$\mathrm{kJ} / \mathrm{mol}$. Based on these data, it can thus be concluded that the effect of physical adsorption will play a dominating role in the adsorption process of CR dye adsorption onto the adsorbents [25] [29].

\subsection{Harkins-Jura Isotherm}

The Harkins-Jura isotherm models for CR adsorption onto watermelon rinds and neem-tree leaves samples are presented in Figure 5 and the relevant isotherm parameters (Table 1) shows that the values of $R^{2}$ are located in the range of $0.9889-0.9908$, which indicate a better fits to the CR adsorption onto watermelon rinds and neem-

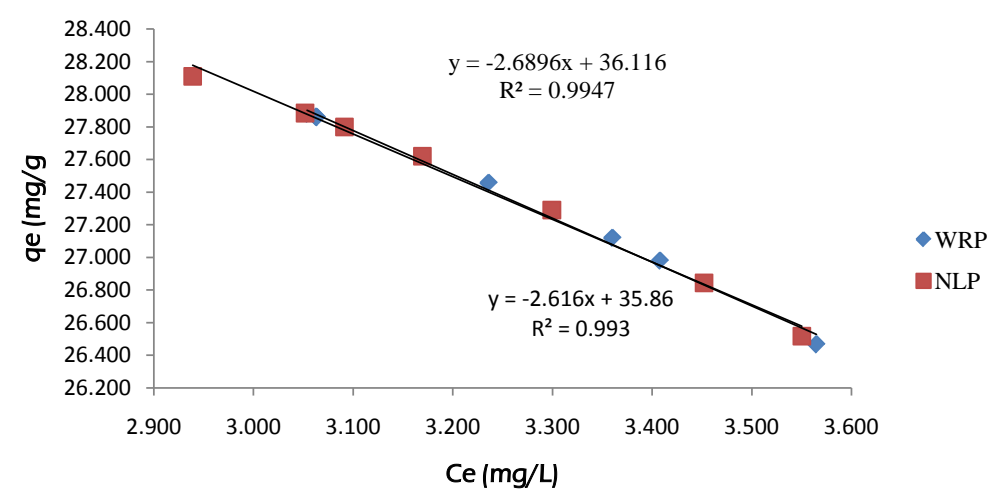

Figure 3. Temkin isotherm plot for CR adsorption onto WRP and NLP.

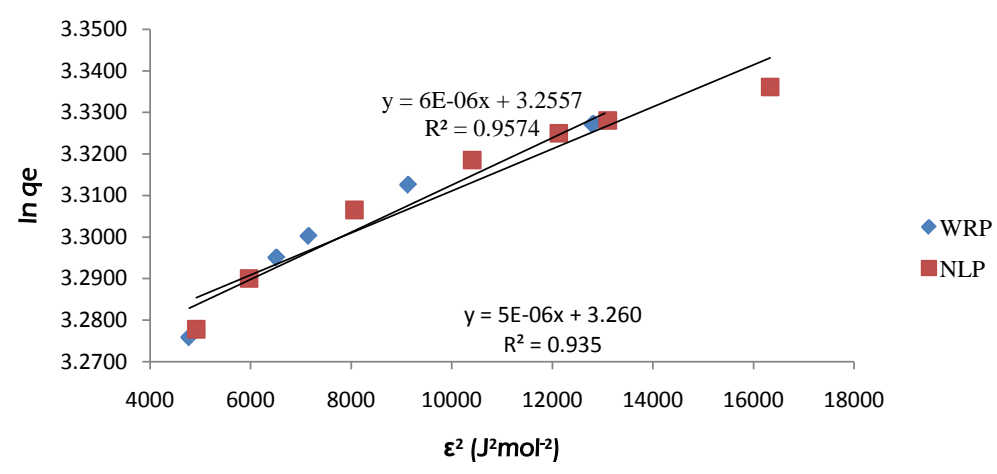

Figure 4. Dubinin-Redushkevich isotherm plot for CR adsorption onto WRP and NLP.

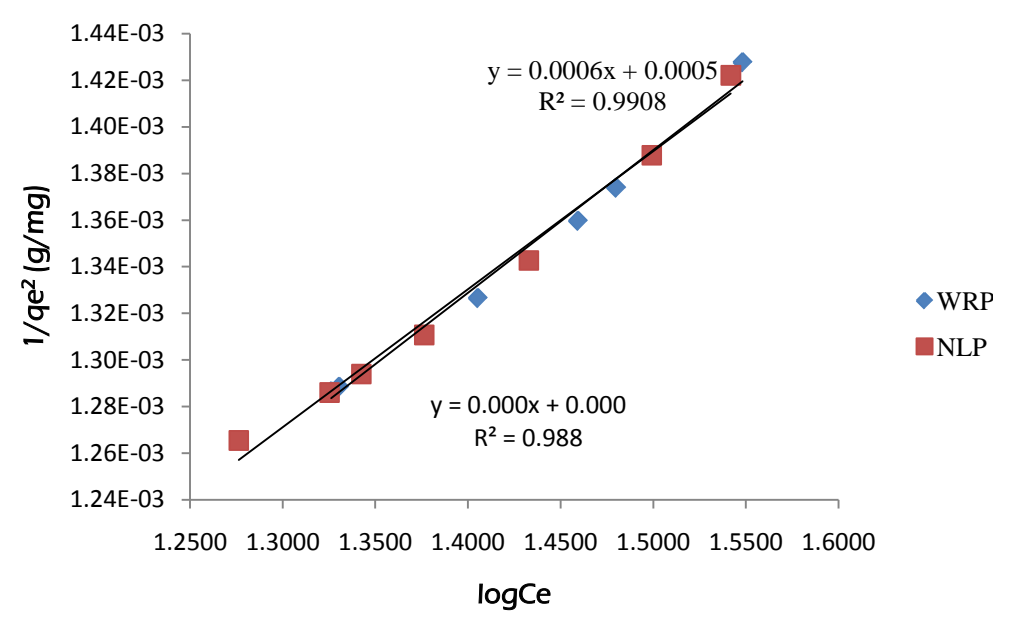

Figure 5. Harkins-Jura isotherm plot for CR adsorption onto WRP and NLP. 
tree leaves samples. This result reveals that CR adsorption onto watermelon rinds and neem-tree leaves samples is in support of the multilayer adsorption rule [30] [31].

\section{Conclusion}

Adsorption of CR dye onto watermelon rinds- and neem leaves-derived adsorbents has been modeled using five two-parameter isotherm equations. The results achieved suggested that all the experimental data followed the tested isotherm models and D-R, Temkin and Harkins-Jura model suggest that the dye is removed from aqueous medium by a multilayer adsorption process.

\section{References}

[1] Ahuja, S. (2009) Handbook of Water Purity and Quality. IWA Publishing, Great Britain, 1-7. http://dx.doi.org/10.1016/B978-0-12-374192-9.00001-7

[2] Rijberman, F.R. (2006) Water Scarcity: Fact or Fiction. Agricultural Water Management, 80, 5-22. http://dx.doi.org/10.1016/j.agwat.2005.07.001

[3] Lee, B., Preston, F., Kooroshy, J., Bailey, R. and Lahn, G. (2012) Resources Futures-A Chatham House Report. The Royal Institute of International Affairs, London.

[4] Damarji, B., Khalaf, H., Duclaux, L. and David, B. (2009) Preparation of $\mathrm{TiO}_{2}$-Pillard Montmorillonite as Photocatalyst Part II: Photocatalytic Degradation of a Textile Azo Dye. Applied Clay Science.

[5] Unuabonah, E.I., Adebowale, K.O. and Dwodu, F.A. (2008) Equilibrium, Kinetics and Sober Design Studies on the Adsorption of Aniline Blue Dye by Sodium Tetraborate-Modified Kaolinite Clay Adsorbent. Journal of Hazardous Materials, 157, 397-409. http://dx.doi.org/10.1016/j.jhazmat.2008.01.047

[6] Zohra, B., Aicha, K., Fatima, S., Nourredin, B. and Zoubir, D. (2008) Adsorption of Direct Red 2 on Bentonite Modified by Cetyltrimethylammonium Bromide. Chemical Engineering Journal, 136, 295-305. http://dx.doi.org/10.1016/j.cej.2007.03.086

[7] Gómez, V., Larrechi, M.S. and Callao, M.P. (2007) Kinetic and Adsorption Study of Acid Dye Removal Using Activated Carbon. Chemosphere, 69, 1151-1158. http://dx.doi.org/10.1016/j.chemosphere.2007.03.076

[8] Gupta, V.K., Kumar, R., Nayak, A., Saleh, T.A. and Barakat, M.A. (2013) Adsorptive Removal of Dyes from Aqueous Solution onto Carbon Nanotubes: A Review. Advances in Colloid and Interface Science, 193-194, 24-34. http://dx.doi.org/10.1016/j.cis.2013.03.003

[9] Santos, S.C.R. and Boaventura, R.A.R. (2008) Adsorption Modelling of Textile Dyes by Sepiolite. Applied Clay Science, 42, 137-145. http://dx.doi.org/10.1016/j.clay.2008.01.002

[10] Bulut, E., Ozcar, M. and Sengil, I.A. (2008) Equilibrium and Kinetic Data and Process Design for Absorption of Congo Red on Bentonite. Journal of Hazardous Materials, 154, 613-622. http://dx.doi.org/10.1016/j.jhazmat.2007.10.071

[11] Özcan, A.S. and Özcan, A. (2004) Adsorption of Acid Dyes from Aqueous Solution onto Acid-Activated Bentonite. Journal of Colloidal and Interface Sciences, 276, 39-46. http://dx.doi.org/10.1016/j.jcis.2004.03.043

[12] Acemioğlu, B. (2004) Adsorption of Congo Red from Aqueous Solution onto Calcium-Rich Fly Ash. Journal of Colloid and Interface Science, 274, 371-379. http://dx.doi.org/10.1016/j.jcis.2004.03.019

[13] Purkait, M.K., Maiti, A., DasGupta, S. and De, S. (2007) Removal of Congo Red Using Activated Carbon and Its Regeneration. Journal of Hazardous Materials, 145, 289-295. http://dx.doi.org/10.1016/j.jhazmat.2006.11.021

[14] Song, Y.L., Li, J.T. and Chen H. (2009) Degradation of C.I. Acid Red 88 Aqueous Solution by Combination of Fenton's Reagent and Ultrasound Irradiation. Journal of Chemical Technology and Biotechnology, 84, 578-583. http://dx.doi.org/10.1002/jctb.2083

[15] Liu, C., Ngo, H.H., Guo, W. and Tung, K. (2012) Optimal Conditions for Preparation of Banana Peels, Sugarcane Bagasse and Watermelon Rind in Removing Copper from Water. Bioresource Technology, 119, 349-354. http://dx.doi.org/10.1016/j.biortech.2012.06.004

[16] Yadla, S.V., Sridevi, V. and Lakshmi, M.V.V.C. (2012) A Review on Adsorption of Heavy Metals from Aqueous Solution. Journal of Chemical, Biological and Physical Sciences, 2, 1585-1593.

[17] Gönen, F. and Serin, D.S. (2012) Adsorption Study on Orange Peel: Removal of Ni (II) Ions from Aqueous Solution. African Journal of Biotechnology, 11, 1250-1258.

[18] Neomagus, H.W.J.P. (2005) Bio-Polymeric Heavy Metal Adsorbing Materials for Industrial Wastewater Treatment (WRC Report No. 1072/1/05).

[19] Nitã, I., Iorgulescu, M., Spiroiu, M.F., Ghiurea, M., Petcu, C. and Cintezã, O. (2007) The Adsorption of Heavy Metal 
Ions on Porous Calcium Alginate Microparticles. Analele Universităt din Bucureşti-Chimie, Anul XVI (serie nouă), 1, 59-67.

[20] Salleh, M.A.M., Mahmoud, D.K., Karim, W.A. and Idris, A. (2011) Cationic and Anionic Dye Adsorption by Agricultural Solid Wastes: A Comprehensive Review. Desalination, 280, 1-13. http://dx.doi.org/10.1016/j.desal.2011.07.019

[21] Sharma, N., Tiwari, D.P. and Singh, S.K. (2012) Decolourization of Synthetic Dyes by Agricultural Waste: A Review. International Journal of Scientific \& Engineering Research, 3, 1-10. http://dx.doi.org/10.15373/22778179/MARCH2014/139

[22] Gopalakrishnan, K., Manivannan, V. and Jeyadoss, T. (2010) Comparative Study of Zn(II), Cu(II) and Cr(VI) from Textile Dye Effluent Using Sawdust and Neem Leaves Powder. E-Journal of Chemistry, 7, S504-S510. http://dx.doi.org/10.1155/2010/506424

[23] Haddadian, Z., Shavandi, M.A., Abidin, Z.Z., Fakhru'l-Razi, A. and Ismail, M.H.S. (2013) Removal of Methyl Orange from Aqueous Solutions Using Dragon Fruit (Hylacereusundatus) Foliage. Chemical Science Transactions, 2, 900910.

[24] Suyamboo, B.K. and Perumal R.S. (2012) Equilibrium, Thermodynamic and Kinetic Studies on Adsorption of a Basic Dye by Citrullus lanatus Rind. Iranica Journal of Energy \& Environment, 3, 23-34. http://dx.doi.org/10.5829/idosi.ijee.2012.03.01.0130

[25] Dada, A.O., Olalekan, A.P., Olatunya, A.M. and Dada, O. (2012) Langmuir, Freundlich, Temkin and Dubinin-Radushkevich Isotherms Studies of Equilibrium Sorption of $\mathrm{Zn}^{2+}$ unto Phosphoric Acid Modified Rice Husk. IOSR Journal of Applied Chemistry, 3, 38-45. http://dx.doi.org/10.9790/5736-0313845

[26] Bhattacharyya, K.G. and Sharma, A. (2004) Azadirachta indica Leaf Powder as an Effective Biosorbent for Dyes: A Case Study with Aqueous Congo Red Solutions. Journal of Environmental Management, 71, 217-229. http://dx.doi.org/10.1016/j.jenvman.2004.03.002

[27] Vimonses, V., Lei, S., Jin, B., Chow, C.W.K. and Saint, C. (2009) Kinetic Study and Equilibrium Isotherm Analysis of Congo Red Adsorption by Clay Materials. Chemical Engineering Journal, 148, 354-364. http://dx.doi.org/10.1016/j.cej.2008.09.009

[28] Yaneva, Z.L. and Georgieva, N.V. (2012) Insights into Congo Red Adsorption on Agro-Industrial Materials-Spectral, Equilibrium, Kinetic, Thermodynamic, Dynamic and Desorption Studies. A Review. International Review of Chemical Engineering, 4, 127-146.

[29] Samarghandi, M.R., Hadi, M., Moayedi, S. and Askari, F.B. (2009) Two-Parameter Isotherms of Methyl Orange Sorption by Pinecone Derived Activated Carbon. Iranica Journal of Environmental Health, Science and Engineering, 6, 285-294.

[30] Abdullah, N.M., Othaman, R., Abdullah, I., Jon, N. and Baharum, A. (2012) Studies on the Adsorption of Phenol Red Dye Using Silica-Filled enr/pvc Beads. Journal of Emerging Trends in Engineering and Applied Sciences (JETEAS), 3, 845-850.

[31] Liu, J. and Wang, X. (2013) Novel Silica-Based Hybrid Adsorbents: Lead(II) Adsorption Isotherms. The Scientific World Journal, 2013, Article ID: 897159. http://dx.doi.org/10.1155/2013/897159 
Scientific Research Publishing (SCIRP) is one of the largest Open Access journal publishers. It is currently publishing more than 200 open access, online, peer-reviewed journals covering a wide range of academic disciplines. SCIRP serves the worldwide academic communities and contributes to the progress and application of science with its publication.

Other selected journals from SCIRP are listed as below. Submit your manuscript to us via either submit@scirp.org or Online Submission Portal.
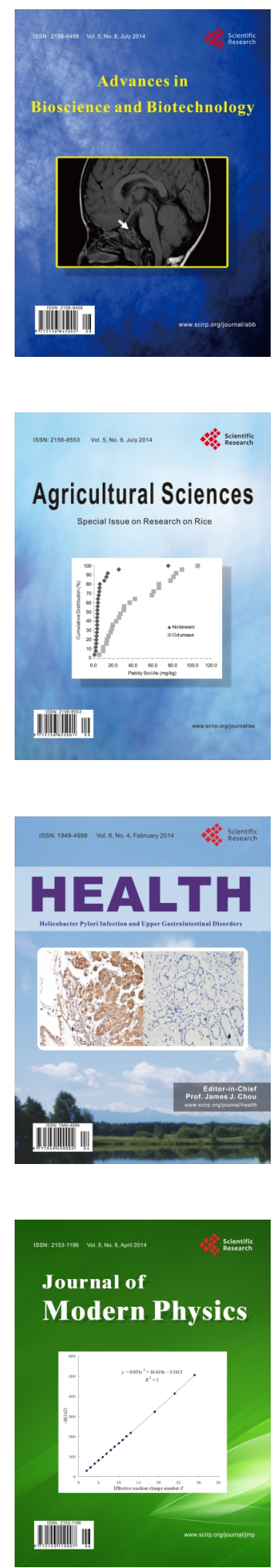
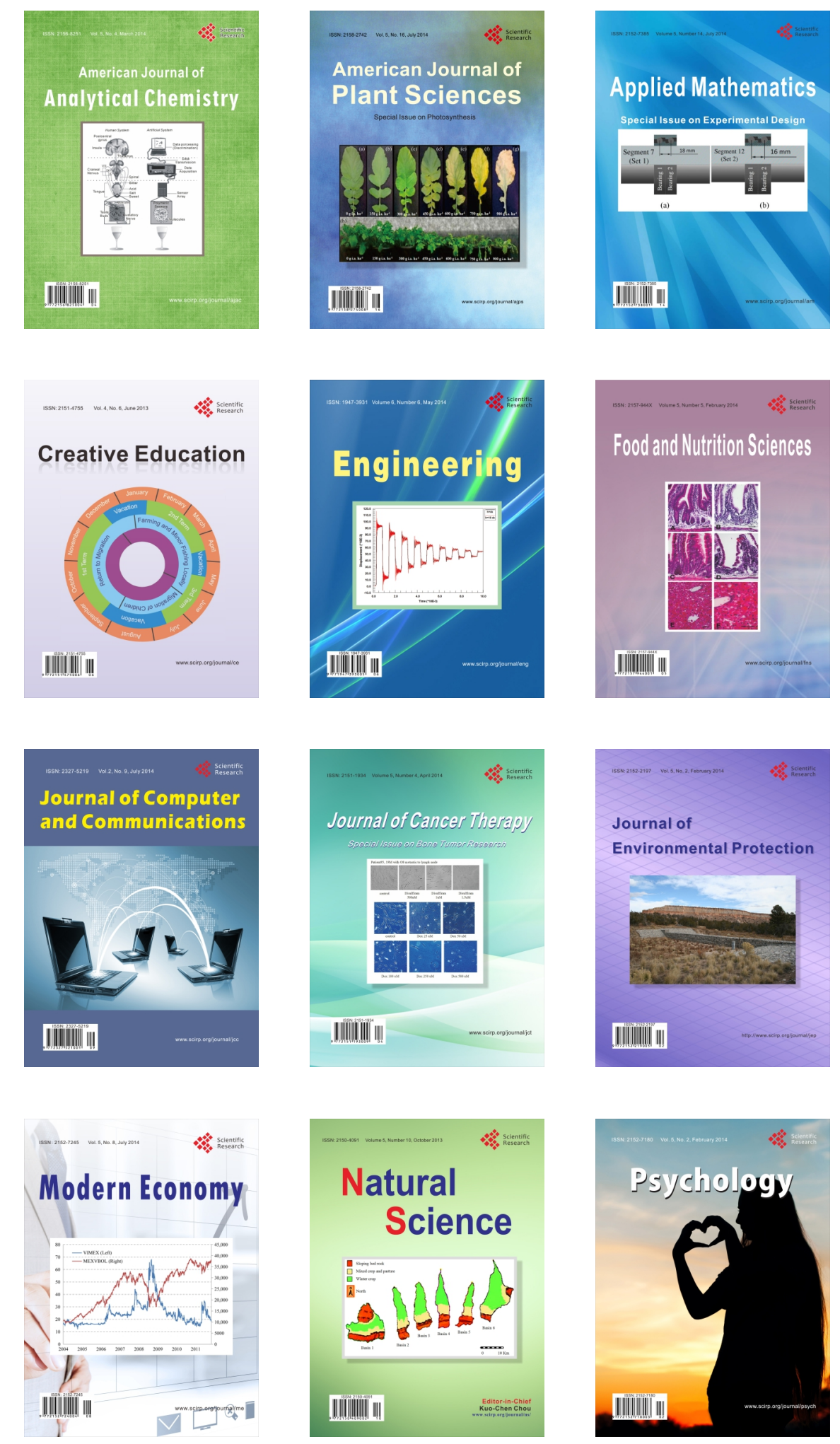